\title{
Synthesis of 1-butoxy-4-tert-butylbenzene under The Effect of Multi-site Phase Transfer Catalysis System - A Kinetic Study
}

\author{
Manickam Sathiyaraj, Perumal Venkatesh* \\ $P G \&$ Research, Department of Chemistry, Pachaiyappa's College, Chennai, Tamil Nadu, \\ 600 030, India.
}

Received: $5^{\text {th }}$ April 2020; Revised: $25^{\text {th }}$ April 2020; Accepted: $26^{\text {th }}$ April 2020; Available online: 30th July 2020; Published regularly: August 2020

\begin{abstract}
Phase transfer catalysis technique proved to be a useful method for synthesizing various organic compounds under heterogeneous reactions and recognized as a viable environmentally friendly. The influence of a new multi site phase transfer catalyst (MPTC) is the synthesis of 1-butoxy-4-tertbutylbenzene from 4-tert-butylphenol with 1-bromobutane (BB) under heterogeneous solid-liquid condition using potassium hydroxide as a base at $60^{\circ} \mathrm{C}$. The higher conversion of 1-bromobutane was achieved by using the synergistic condition of multi-site phase transfer catalyst in better efficacy. The reaction rate enhanced by decreases the volume of water. The apparent the reaction rate was found to be pseudo-first order kinetics. The apparent rate constant was increased linearly with the increase in the concentration of various parameters, such as: MPTC, temperature, potassium hydroxide, and stirring speed. The activation energy $\left(E_{\mathrm{a}}\right)$ was also calculated through the Arrhenius plot. Copyright $\mathbb{C} 2020$ BCREC Group. All rights reserved
\end{abstract}

Keywords: MPTC; phase transfer catalysis; 4-(tert-butyl)phenol; 1-bromobutane; kinetics; 1-butoxy-4(tert-butyl)benzene

How to Cite: Sathiyaraj, M., Venkatesh, P. (2020). Synthesis of 1-butoxy-4-tert-butylbenzene under The Effect of Multi-site Phase Transfer Catalysis System - A Kinetic Study. Bulletin of Chemical Reaction Engineering \& Catalysis, 15(2), 405-414 (doi:10.9767/bcrec.15.2.7519.405-414)

Permalink/DOI: https://doi.org/10.9767/bcrec.15.2.7519.405-414

\section{Introduction}

Phase transfer catalysis (PTC) has been considered as one of the better efficient tools, in the field of chemistry, because of its simplicity, high conversion, beneath very gentle reaction condition and ecofriendly nature. The PTC has been proved to be economic approach to behavior reaction among two completely immiscible reactants [1-4]. Besides this, they pose toll on environmental pollution as well PTC is an estab-

* Corresponding Author.

Email: pvenkatesh175@gmail.com; venkat_28@hotmail.com (P.Venkatesh) lished method in which there is an equal proportions of both aqueous with organic phases which will overcomes the difficulties associated with side product formations [5]. Recently, PTC is usually used in industrial process [6]. The economic success of chemical and related industries depends highly on the development of new process and retrofitting old process which are environmentally benign [7-8]. The advantages with phase transfer catalyst method includes easy handling of the reactions, better product yield, improved reaction rate, and specific selectivity of the reactions. Notably, these PTC based organic synthesis has wide applications in chemi- 
cal manufacturing industries, viz - pharmaceutical drugs, lubricants, pesticides, dyes, agrochemical, flavors, pollution control and monomers for polymer synthesis [9]. Moreover, PTC was employed in the chemical synthesis of oxidation, reduction, polymerizations, transition metal co-catalyzed reactions, addition and condensations reactions, etc. The phase transfer catalyst can be classified into two types, i.e. liquid-liquid biphase PTC [10-12] and solidliquid two phase PTC [13-14]. In this type of solid liquid phase transfer catalyst without using of water, the rate of the reaction was very elevated, almost insignificant subproducts and embrace high in yields of products.

Theory of multi-sited phase transfer catalyst (MPTC) $\left(\mathrm{QX}_{2}\right)$ was proposed by Idoux et al. by this reaction they have prepared phosphonium and quaternary onium ions incorporating more than one active site per molecule. The capability of the catalytic performance of these 'multisite' PTCs towards simple $\mathrm{S}_{\mathrm{N}} 2$ reactions and a few weak nucleophile-electrophile $\mathrm{S}_{\mathrm{N}} \mathrm{Ar}$ reactions are have been reported [15]. The most important value for multi site PTCs is capability to transfer more number of anionic species $\left(\mathrm{M}^{+} \mathrm{Y}\right)$ from aqueous phase to organic phase. In rather than the single-site quaternary onium PTC can move only one molecule of anionic species, i.e. $\mathrm{M}^{+} \mathrm{Y}$ - from aqueous phase per cycle. In particular, much insistence has been given to economy of scale and competence of onium salts mainly for the industrial scale synthesis of organic compounds. Hence, with a single active site, this commercial PTC has a limitation which is either soluble or insoluble at any given time. To overcome these limits, the growth of multi-site PTCs (MPTCs) is more advantageous because it has more than one active site with improved selectivity and specific reactivity [16]. Soluble MPTC contains two and three active sites to catalyze using the several organic reactions reported Balakrishnanan et al. [17-18]. Murugan et al. [19] also investigated kinetics of dichlorocarbene addition of citronellal using new multi-sit PTC containing two and four active sites. Wang and Lee [20] reported a kinetic study on bisphenol A and allyl bromide by using novel MPTC contain dual active site and showed that MPTC exhibit more reactivity than single site. Many author reported more than a few MPTC mediated alkylation and arylation [21-23], polymerization [24-25], epoxidation [26], asymmetric synthesis [27] reactions. $\mathrm{N}^{1}, \mathrm{~N}^{1}, \mathrm{~N}^{2}, \mathrm{~N}^{2}$-tetramethyl-ethylenediamine is an ethylenediamine derivative in which every nitrogen having two methyl groups. It is broadly employed as a catalyst in polymerization and organic reactions. It reacts with aryl halide and gives a multi-site quaternary onium phase transfer catalyst. 4-tert-butylphenol is a member of the class of phenols that is phenol alternate with a tert-butyl group at position 4 . Generally, 4-tert-butylphenol is a phenol derivative used in the polymer industry [28].

In this present study, we have synthesized the MPTC viz. $\mathrm{N}^{1}, \mathrm{~N}^{2}$-dibenzyl- $\mathrm{N}^{1}, \mathrm{~N}^{1}, \mathrm{~N}^{2}, \mathrm{~N}^{2}$ tetramethylethane-1,2-diaminium dibromide (Scheme 1) and used as an effective catalyst for the synthesis of 1-butoxy-4-tert-butylbenzene from 4-tert-butylphenol with 1-bromobutane (BB) under heterogeneous solid-liquid condition (Scheme 2). The product obtained was confirmed by ${ }^{1} \mathrm{H}$ NMR, ${ }^{13} \mathrm{C}$ NMR. The kinetic study of O-alkylation under controlled MPTC reaction conditions will be interesting so that the study of kinetic parameters has been followed.

\section{Materials and Methods}

\subsection{Materials}

All the reagents, including, 4-tertbutylphenol, 1-bromobutane, $\mathrm{N}^{1}, \mathrm{~N}^{1}, \mathrm{~N}^{2}, \mathrm{~N}^{2}$ tetramethylethane-1,2-diamine (Aldrich), benzylbromide (Merck) biphenyl, tetrabutylammonium bromide (TBAB), tetrabutylammonium chloride(TBAC), tetrabutylammonium iodide (TBAI), tetrahexylammonium bromide (THAB), tetraoctylammonium bromide (TOAB), potassium hydroxide, ethyl acetate,

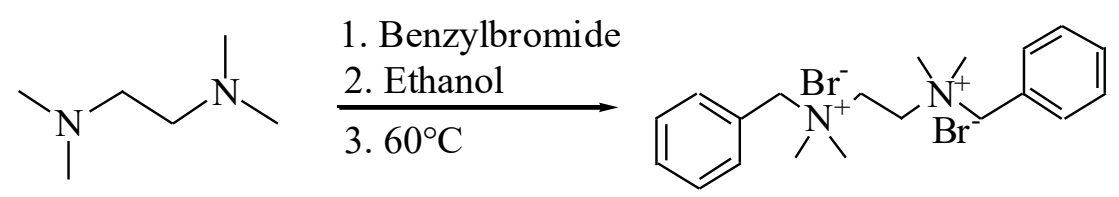

$\mathrm{N}^{1}, \mathrm{~N}^{1}, \mathrm{~N}^{2}, \mathrm{~N}^{2}$-tetramethylethane-1,2-diamine

$\mathrm{N}^{1}, \mathrm{~N}^{2}$-dibenzyl-N ${ }^{1}, \mathrm{~N}^{1}, \mathrm{~N}^{2}, \mathrm{~N}^{2}$-tetramethylethane1,2-diaminium dibromide

Scheme 1. Synthesis of $\mathrm{N}^{1}, \mathrm{~N}^{2}$-dibenzyl- $\mathrm{N}^{1}, \mathrm{~N}^{1}, \mathrm{~N}^{2}, \mathrm{~N}^{2}$-tetramethylethane-1,2-diaminium dibromide (MPTC). 
toluene, chlorobenzene, benzene, ethanol, diethyl ether and other reagents for synthesis were of guaranteed grade (GR) chemicals and were used without further purification.

\subsection{Instrumentation}

${ }^{1} \mathrm{H}$ NMR and ${ }^{13} \mathrm{C}$ spectra were recorded using DMSO and $\mathrm{CDCl}_{3}$ as an internal standard, respectively, on a Bruker $500 \mathrm{MHz}$. Gas Chromatography were recorded using Agilent GC-Varian 3700 model having dimension of 30 $\mathrm{m} \times 0.525 \mathrm{~mm}$ i.d. capillary column with $100 \%$ poly(dimethyl siloxanen), injection temperature, $250{ }^{\circ} \mathrm{C}$, FID detector $\left(300{ }^{\circ} \mathrm{C}\right)$, using biphenyl as a internal standard, yield of the sample was determined.

\subsection{Synthesis of A New Multi-site Phase- transfer Catalyst (MPTC)}

A mixture of $\mathrm{N}^{1}, \mathrm{~N}^{1}, \mathrm{~N}^{2}, \mathrm{~N}^{2}$ tetramethylethane-1,2-diamine $\quad(3 \mathrm{~g}, \quad 25.81$ $\mathrm{mmol}$ ), benzylbromide (5 g, $29.23 \mathrm{mmol}$ ) and 70 $\mathrm{mL}$ of ethanol was placed in a $250 \mathrm{~mL}$ three necked round bottomed Pyrex flask were refluxed at $60^{\circ} \mathrm{C}$ for $24 \mathrm{~h}$ and in an oxygen free atmosphere. The solvent was completely removed under vacuum. The colorless solid obtained was onium salt, i.e. $\mathrm{N}^{1}, \mathrm{~N}^{2}$-dibenzyl$\mathrm{N}^{1}, \mathrm{~N}^{1}, \mathrm{~N}^{2}, \mathrm{~N}^{2}$-tetramethylethane-1,2-diaminium dibromide, and it was washed with n-hexane and stored in $\mathrm{CaCl}_{2}$ packed desiccators. Yield: 96.0\%; ${ }^{1} \mathrm{H}$ NMR $\left(500 \mathrm{MHz}, \mathrm{DMSO}-d_{6}\right): \delta 3.39$ $\left(12 \mathrm{H}, \mathrm{CH}_{3}\right), 3.79\left(4 \mathrm{H}, \mathrm{N}^{+}-\mathrm{CH}_{2}\right), 4.74-4.68(4 \mathrm{H}$, Aromatic $\left.\mathrm{CH}_{2}\right)$, 7.63-7.55 (10H, Aromatic $\left.\mathrm{CH}\right)$, ${ }^{13} \mathrm{C}$ NMR (125 MHz, DMSO- $\left.d_{6}\right): 49.54\left(\mathrm{CH}_{3}\right)$, $55.90\left(\mathrm{CH}_{2}\right), \quad 67.16\left(\mathrm{~N}^{+}-\mathrm{CH}_{2}\right), \quad 129.10, \quad 130.61$, 133.27 (Aromatic $\mathrm{CH}$ ). Elemental analysis: Calculated: C 52.20, H 6.82, N 6.22, Br 34.76, Obs (\%). C 52.09, H 6.54, N 6.10, Br 34.26.

\subsection{Synthesis of 1-butoxy-4-(tert-butyl)benzene}

The 4-tert-butylphenol (2 g, $13.31 \mathrm{mmol})$ was added to powdered $\mathrm{KOH} \mathrm{(10} \mathrm{g} \mathrm{in} 3 \mathrm{~mL}$ water) under overhead stirring for few minutes to produce 4-tert-butylphenol anion. To this 1- bromobutane (1.82 g, $13.31 \mathrm{mmol})$ and the synthesized $\mathrm{N}^{1}, \mathrm{~N}^{2}$-dibenzyl-N ${ }^{1}, \mathrm{~N}^{1}, \mathrm{~N}^{2}, \mathrm{~N}^{2}$ tetramethylethane-1,2-diaminium dibromide (MPTC) (3 mol\%) in chlorobenzene $(30 \mathrm{~mL})$ were added slowly with vigorous stirring and heated at $60{ }^{\circ} \mathrm{C}$ for $2 \mathrm{~h}$. The product formed was evidenced by TLC. Isolation of the product was done by simple extraction ethyl acetate. Extract was collected and solvent was evaporated under reduced pressure. To obtain a pure derivative 1-butoxy-4-tert-butylbenzene the crude sample was subjected to column chromatography. The column was packed with silica and employed hexane and ethyl acetate (9:1) as an eluent. The structure was confirmed using ${ }^{1} \mathrm{H}$ NMR and ${ }^{13} \mathrm{C}$ NMR spectra.

${ }^{1} \mathrm{H} \mathrm{NMR}\left(\mathrm{CDCl}_{3}\right): \delta 0.978\left(3 \mathrm{H}-\mathrm{CH}_{3}\right), 1.293-$ $1.458\left(2 \mathrm{H}-\mathrm{t}-\mathrm{CH}_{3}\right), \delta 1.488-1.518\left(2 \mathrm{H}-\mathrm{CH}_{2}\right), \delta$ $1.719-1.775\left(2 \mathrm{H}-\mathrm{CH}_{2}\right), \delta 3.934\left(2 \mathrm{H}-\mathrm{CH}_{2}\right), \delta$ $6.821-6.838(1 \mathrm{H}-\mathrm{Ar}-\mathrm{CH}), \delta 7.275-7.293(1 \mathrm{H}-$ Ar-CH). ${ }^{13} \mathrm{C}$ NMR $\left(\mathrm{CDCl}_{3}\right): \delta 14.001\left(\mathrm{CH}_{3}\right), \delta$ 19.430, 31.164, $67.739\left(\mathrm{CH}_{2}\right), 31.679,34.164(\mathrm{t}-$ C- $\left.\mathrm{CH}_{3}\right), 114.072,126.287$ (Ar-CH), 143.212, 157.042 (Ar-C). Elemental analysis; Calculated: C 80.56, H 11.81, O 7.79. Obs (\%). C 80.36, H 11.10, O 7.32 .

\subsection{Kinetics Measurements}

The kinetics of reaction between well powdered $\mathrm{KOH}$ (10 g), biphenyl (0.2 g, internal standard), chlorobenzene (30 mL, solvent) and 4-tert-butylphenol (2 g, $13.31 \mathrm{mmol}), \quad 1$ bromobutane $(1.82 \mathrm{~g}, 13.31 \mathrm{mmol})$ in the presence newly synthesized multi-site phase transfer catalyst ( $3 \mathrm{mmol} \%)$. The reaction mixture was taken in three necked Pyrex round bottom flask $(250 \mathrm{~mL})$ with constant stirring at 600 rpm. Phase separation of the reaction mixture was immediate on arresting the stirring. Sample were collected from the organic layer at regular intervals of time and poured in a glass vial containing anhydrous $\mathrm{CaCl}_{2}$ (to remove moisture) and $0.5 \mathrm{~mL}$ chlorobenzene. The kinetics was followed by examined the amount of 1-bromobutane (limiting agent) disappeared using gas chromatography.<smiles>CC(C)(C)c1ccc(O)cc1</smiles>

4-tert-butylphenol
1. $\mathrm{KOH}$

\section{1-bromobutane}

3. MPTC

4. $60^{\circ} \mathrm{C}, 600 \mathrm{rpm}$

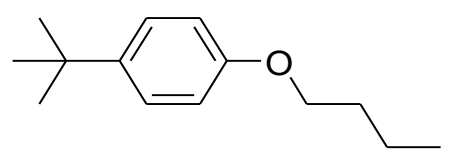

1-butoxy-4-tert-butylbenzene

Scheme 2. Synthesis of 1-butoxy-4-tert-butylbenzene. 


\section{Results and Discussion}

\subsection{Influence of Stirring Speed}

With a view the influence agitation speeds on the reaction of 1-butoxy-4-tert-butyl benzene from 4-tert-butylphenol and 1-bromobutane using MPTC, the reaction was studied by varying the agitation speed range 0 to $800 \mathrm{ppm}$. There are significant increases in the reaction rate with raise in the agitation speed from 0 to 800 $\mathrm{rpm}$. The rate of the reaction increases linearly as the stirring speed increases from 0-600 rpm (Table 1). Nevertheless, on further increasing the agitation speed from 600 to 800 , there is no significance improvement in the reaction rate constant. Typically since the interfacial region per unit volume of scattering increased linearly with raising the agitation speed till $600 \mathrm{rpm}$ is reached; there is no major increase within the interfacial region per unit volume of scattering with the comparable increase in the stirring speed. Dissolving of $\mathrm{C}_{10} \mathrm{H}_{13} \mathrm{O}-\mathrm{K}^{+}$in chlorobenzene increases in organic solvents with increases in agitation speed. This verify that the reaction of $\mathrm{C}_{10} \mathrm{H}_{13} \mathrm{O}-\mathrm{K}^{+}$and 1-bromobutane was carried out in a homogeneous solution, i.e. $\mathrm{C}_{10} \mathrm{H}_{13} \mathrm{O} \cdot \mathrm{K}^{+}$dissolves steadily in organic solvent in the presence of multi-site phase transfer catalyst to form $\mathrm{Q}^{2+}\left(\mathrm{C}_{10} \mathrm{H}_{13} \mathrm{O}^{-}\right)$at interphase. Then, the formed intermediate $\mathrm{Q}^{2+}$ $\left(\mathrm{C}_{10} \mathrm{H}_{13} \mathrm{O}\right)$ reacted with 1 -bromobutane to produce 1-butoxy-4-tert-butylbenzene in the organic phase. Thus increasing the agitation speed changes in the particle size of the dis-

Table 1. Influence of Stirring speed on the reaction condition: $10 \mathrm{~g}$ of $\mathrm{KOH}$, in $3 \mathrm{~mL} \mathrm{H} \mathrm{H}_{2} \mathrm{O}, 0.2$ $\mathrm{g}$ of biphenyl (internal standard), $13.31 \mathrm{mmol}$ of 4-tert-butylphenol, $13.31 \mathrm{mmol}$ of 1 bromobutane, $3 \mathrm{~mol} \%$ of MPTC, $30 \mathrm{~mL}$ of chlorobenzene, $60^{\circ} \mathrm{C}$.

\begin{tabular}{cc}
\hline Stirring speed $(\mathrm{rpm})$ & $k_{\text {app }} \times 10^{-3}, \mathrm{~min}^{-1}$ \\
\hline 0 & 9.25 \\
100 & 11.60 \\
200 & 17.34 \\
300 & 19.59 \\
400 & 20.45 \\
500 & 21.87 \\
600 & 22.32 \\
700 & 22.96 \\
800 & 23.14 \\
\hline
\end{tabular}

persed phase. Accordingly, the agitation speed was set at $600 \mathrm{rpm}$ for considering the reaction occurrence from which the resistance of masstransfer remains at a consistent esteem. Makozha and Starks [29-30] explain extraction and interfacial reaction mechanism, the two phase reaction system, the influence of stirring speed on the rate of the reaction. Wang et al. [31] reported the kinetic study of dichlorocyclopropanation PTC mediated dichlorocarbene addition suggested an interfacial mechanism.

\subsection{Influence of Concentration of 1-} bromobutane

To investigate the influence of concentration of 1-bromobutane (BB) on the kinetics of synthesis 1-butoxy-4-tert-butylbenzene under multi-site phase transfer catalyst condition, the amount of 1-bromobutane was studied that range of 1.8 to $2.6 \mathrm{~mL}$ keeping other experiment parameters conditions. The apparent rate constant of the reaction increases with the increases in the amount of BB was shown in Table 2. Synergetic effect of linear plot was due to further more number of active sites in MPTC and high concentration of 1-bromobutane and these increases the reaction rate. A similar result was investigated in the consideration of Calkylation reaction of phenylacetonitrile and phenyl acetone [17] with 1-bromobutane under PTC condition.

\subsection{Influence of Potassium Hydroxide Concen- tration}

In this work, the effect of the amount of $\mathrm{KOH}$ on the reaction conversion of etherification was investigated. The rate of 1-butoxy-4tert-butylbenzene powerfully depends on the potency of the potassium hydroxide. Kinetics

Table 2. Influence of concentration of 1bromobutane on the reaction condition: $10 \mathrm{~g}$ of $\mathrm{KOH}$, in $3 \mathrm{~mL} \mathrm{H}_{2} \mathrm{O}, 0.2 \mathrm{~g}$ of biphenyl (internal standard), $13.31 \mathrm{mmol}$ of 4-tert-butylphenol, 3 $\mathrm{mol} \%$ of MPTC, $30 \mathrm{~mL}$ of chlorobenzene, $60^{\circ} \mathrm{C}$, $600 \mathrm{rpm}$.

\begin{tabular}{cc}
\hline 1-bromobutane $(\mathrm{mL})$ & $k_{\text {app }} \times 10^{-3}, \mathrm{~min}^{-1}$ \\
\hline 1.8 & 19.45 \\
2.0 & 22.32 \\
2.2 & 22.07 \\
2.4 & 22.73 \\
2.6 & 23.12 \\
\hline
\end{tabular}


was carried by changing the amount of $\mathrm{KOH}$ from 6 to $16 \mathrm{~g}$ (volume of water $3 \mathrm{~mL}$ constant) keeping similar reaction conditions. Figure 1 gives the plot of rate constant vs. concentration of potassium hydroxide. The rate constant extremely increased with increase in hydroxide ion basicity, i.e. the rate constant was found to increase with an increase in $\mathrm{KOH}$ concentration. This suggests that the hydroxide ion are less solvated by water molecule and there by the activity of hydroxide ion. Balakrishanan et al. [16] also investigate the study of phase transfer catalyst mediated $\mathrm{C}$-alkylation of indene with dibromobutane was observed rate constant extremely augmented with increase in basicity of hydroxide ion. In common, effective of the hydroxide in analyze raise due to the dependence of hydroxide basicity on hydration. Further, the reaction rate also increases with addition of droplet of water as in other SL-PTC (solid-liquid phase transfer catalyst). This is because the availability of $\mathrm{OH}^{-}$increasing resulting in the formation of much more anions $\mathrm{C}_{10} \mathrm{H}_{13} \mathrm{O} \cdot \mathrm{K}^{+}$.

\subsection{Influence of Concentration MPTC}

The effect of MPTC concentration (viz., $\mathrm{N}^{1}, \mathrm{~N}^{2}$-dibenzyl- $\mathrm{N}^{1}, \mathrm{~N}^{1}, \mathrm{~N}^{2}, \mathrm{~N}^{2}$-tetramethylethane1,2-diaminium dibromide) on the $\mathrm{O}$-alkylation of 4-tert-butylphenol was performed in the concentration range of $1 \mathrm{~mol} \%$ to $6 \mathrm{~mol} \%$ with all further experimental parameters kept constant. There was a comparative increase in the concentration of MPTC up to $3 \mathrm{~mol} \%$. The in-

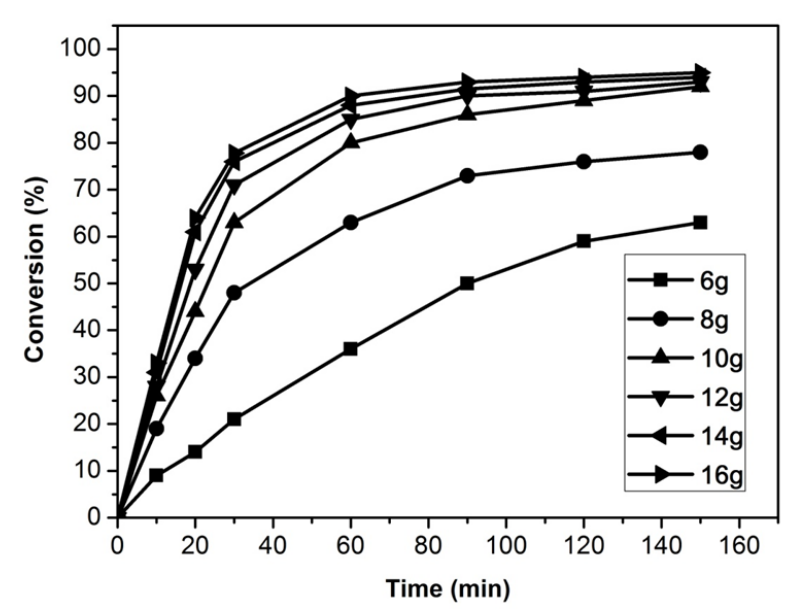

Figure 1. Influence of potassium hydroxide concentration on the apparent rate constant: $0.2 \mathrm{~g}$ of biphenyl (internal standard), $13.31 \mathrm{mmol}$ of 4 -tert-butylphenol, $13.31 \mathrm{mmol}$ of 1-bromobutane, $3 \mathrm{~mol} \%$ of MPTC, $30 \mathrm{~mL}$ of chlorobenzene, $60^{\circ} \mathrm{C}, 600 \mathrm{rpm}$. fluence of amount of catalyst on reaction rate was shown in Figure 2. In common, reactivity increased with an increase in the amount of quaternary ammonium salt. It bare that more catalyst resulted in very much faster initial reaction, leads to more inorganic salt formed and deposited on the particle surface. Hence, reducing compose contact with the catalyst and the solid reactant, and hence the reaction rate was rapidly diminish and concluded in the late reaction period ( $>30 \mathrm{~min})$ with small divergence to pseudo-first-order kinetics. The small amount of water (trace) can capably encourage the solubilization of the solid reactant and thus improve the formation of catalytic intermediate $\mathrm{Q}^{2+}\left(\mathrm{C}_{10} \mathrm{H}_{13} \mathrm{O} \cdot \mathrm{K}^{+}\right)$.

\subsection{Influence of Temperature}

As for the influence of temperature on their action between 4-tert-butylphenol and 1bromobutane was carried out in the temperature range of $20-60{ }^{\circ} \mathrm{C}$ keeping the other experimental parameters. It is clear that the reactivity is increased with an increase in the temperature, and it follows a pseudo first order rate law (Figure 3). Usually, the etherification is endothermic without any side reaction. The solubility of aqueous phase the reactant of 4 tert-butylphenol in the aqueous phase augmented by increasing the temperature. Hence, at higher temperature the apparent rate constant is increased. Arrhenius plot is given by plotting $-\ln k_{a p p}$ against temperature shown in Figure 4 . From this $\mathrm{E}_{\mathrm{a}}=56.71$ kJ.mol ${ }^{-1}$ was cal-

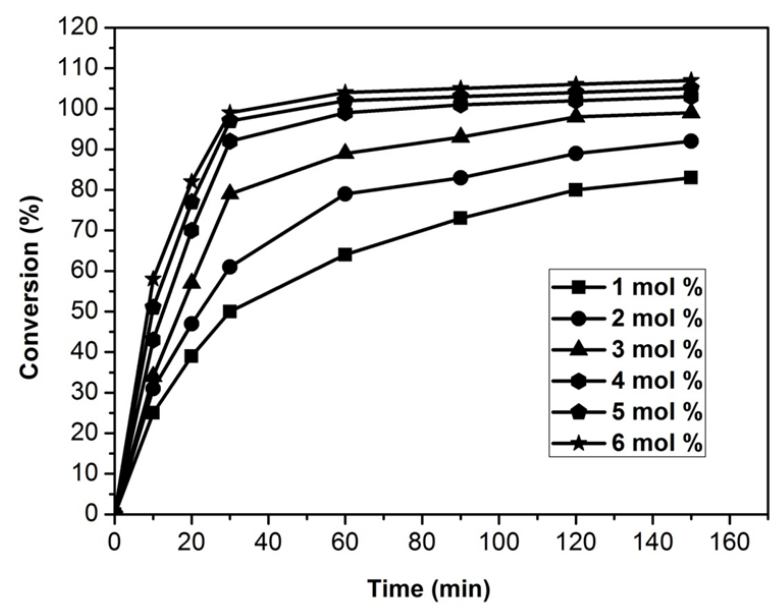

Figure 2. Influence of amount of Multi-site phase transfer catalyst on the apparent rate constant: $10 \mathrm{~g}$ of $\mathrm{KOH}$, in $3 \mathrm{~mL} \mathrm{H} \mathrm{H}_{2} \mathrm{O}, 0.2 \mathrm{~g}$ of biphenyl (internal standard), $13.31 \mathrm{mmol}$ of 4 tert-butylphenol, $13.31 \mathrm{mmol}$ of 1-bromobutane, $30 \mathrm{~mL}$ of chlorobenzene, $60{ }^{\circ} \mathrm{C}, 600 \mathrm{rpm}$. 
culated. If the reaction was under chemical reaction control condition, activation energy would be larger than $10 \mathrm{kcal} / \mathrm{mol}$ and if masstransfer control condition, activation energy was less than $10 \mathrm{kcal} / \mathrm{mol}$. MPTC assisted solid-liquid reaction was kinetically controlled and so the mass transfer in the interface influence of increases the activation energy. Hence, apparent activation energy value proves that the etherification reaction is under chemical reaction control with high agitation speed.

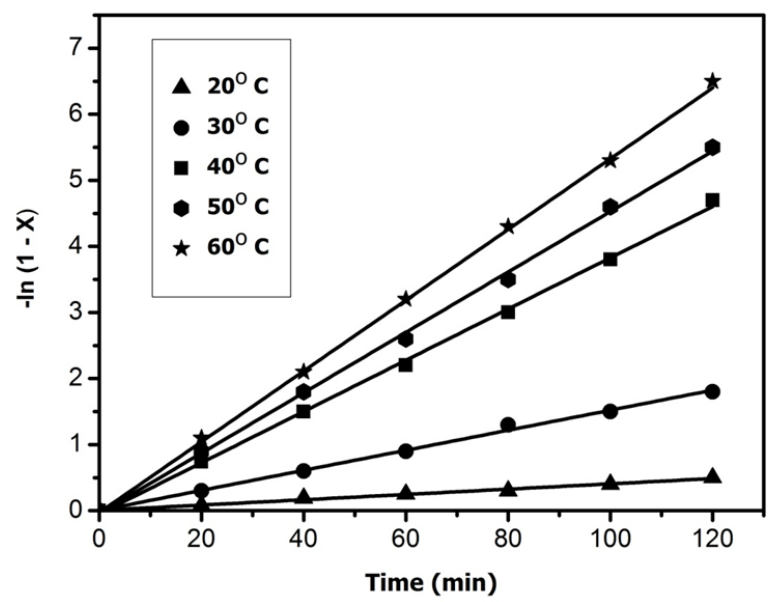

Figure 3. Influence of the temperature on the apparent rate constant: $10 \mathrm{~g}$ of $\mathrm{KOH}$, in $3 \mathrm{~mL}$ $\mathrm{H}_{2} \mathrm{O}, 0.2 \mathrm{~g}$ of biphenyl (internal standard), $13.31 \mathrm{mmol}$ of 4-tert-butylphenol, $13.31 \mathrm{mmol}$ of 1-bromobutane, $3 \mathrm{~mol} \%$ of MPTC, $30 \mathrm{~mL}$ of chlorobenzene, $600 \mathrm{rpm}$.

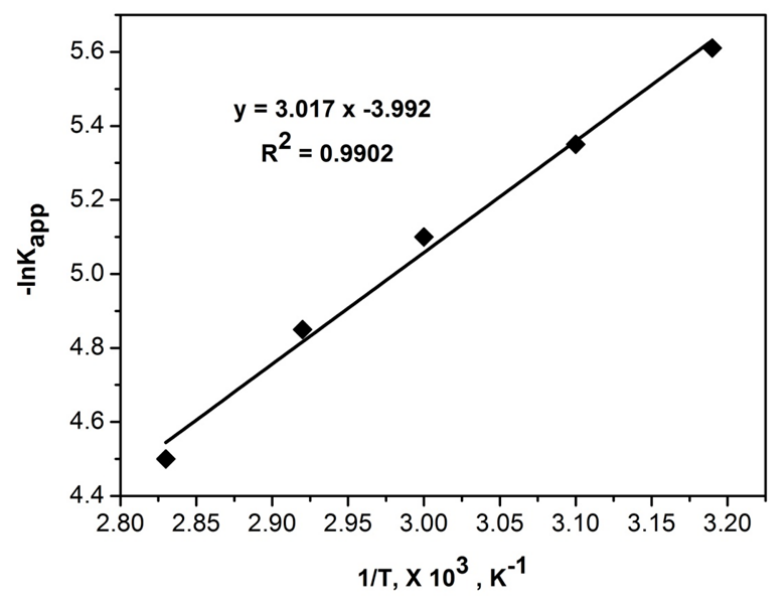

Figure 4. Arrhenius plot; $10 \mathrm{~g}$ of $\mathrm{KOH}$ in $3 \mathrm{~mL}$ $\mathrm{H}_{2} \mathrm{O}, 0.2 \mathrm{~g}$ of biphenyl (internal standard), $13.31 \mathrm{mmol}$ of 4-tert-butylphenol, $13.31 \mathrm{mmol}$ of 1-bromobutane, $3 \mathrm{~mol} \%$ of MPTC, $30 \mathrm{~mL}$ of chlorobenzene, $600 \mathrm{rpm}$.

\subsection{Influence of Volume of Water}

The effect of volume of water on the rate of the etherification was investigated in the range of 0 to $15 \mathrm{~mL} 10 \mathrm{~g}$ of $\mathrm{KOH}$. The reaction was found to be pseudo first order rate law. The plot of product conversion versus volume of water is given Figure 5. The apparent rate constant slightly increased with an increase in the volume of water $(0-15 \mathrm{~mL})$ and then decreased with further increases in the amount of water (3-15 mL). In the absence of water, the product yield was about $40 \%$ in $120 \mathrm{~min}$, so that it was enormously increased to $90.3 \%$ by just $3 \mathrm{~mL}$ of water in system combined addition of water to $15 \mathrm{~mL}$, and the reaction rate gradually reduced. Addition of $3 \mathrm{~mL}$ of water increases the rate attributed to water solubility a part of solid reactant to the formation $\mathrm{Q}^{2+}\left(\mathrm{C}_{10} \mathrm{H}_{13} \mathrm{O}^{-} \mathrm{K}^{+}\right)$ in the interface require and thus enhance the reaction rate. Increased addition of water decreases the effective concentration of $\mathrm{Q}^{2+}$ $\left(\mathrm{C}_{10} \mathrm{H}_{13} \mathrm{O}-\mathrm{K}^{+}\right)$in the interface and thereby decreasing the rate of the reaction. The reaction was sluggish in the absence of water yielding a low percentage of product formation. The formation of $\mathrm{Q}^{2+}\left(\mathrm{C}_{10} \mathrm{H}_{13} \mathrm{O}^{-} \mathrm{K}^{+}\right)$is maximum and concentrated in the interface leads to bulk organic phase reaction at $3 \mathrm{~mL}$ optimum volume of water.

\subsection{Influence of Various Phase-Transfer Cata-} lysts

Quaternary ammonium salts are used as a phase-transfer catalysts to improve the reac-

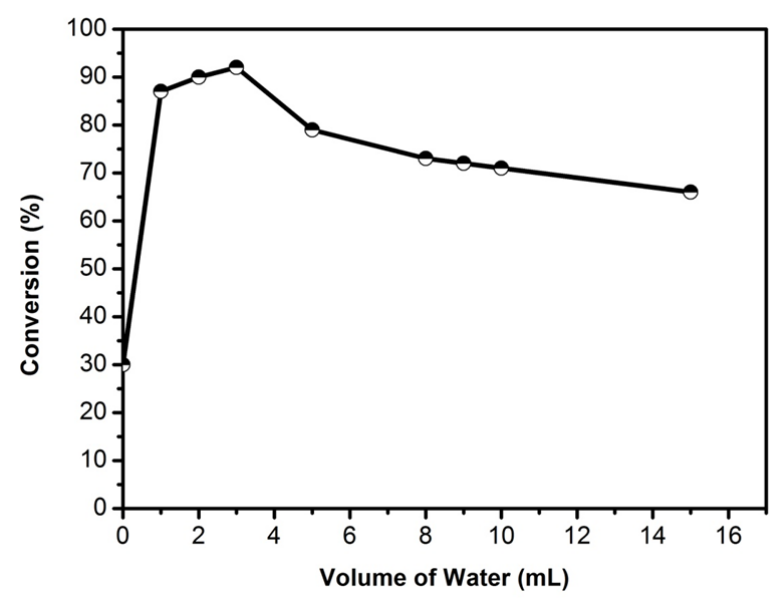

Figure 5. Influence of the volume of water on the apparent rate constant: $10 \mathrm{~g}$ of $\mathrm{KOH}, 0.2 \mathrm{~g}$ of biphenyl (internal standard), $13.31 \mathrm{mmol}$ of 4-tert-butylphenol, $13.31 \mathrm{mmol}$ of 1 bromobutane, $3 \mathrm{~mol} \%$ of MPTC, $30 \mathrm{~mL}$ of chlorobenzene, $60{ }^{\circ} \mathrm{C}, 600 \mathrm{rpm}$. 
tion rate. Several PTC, namely tetraoctylammonium bromide (TOAB), tetrahexylammonium bromide (THAB), tetrabutylammonium iodide (TBAI), tetrabutylammonium bromide (TBAB), and tetrabutylammonium chloride (TBAC), were employed to evaluate the efficiency of MPTC in the $\mathrm{O}$-alkylation of 4 -tert-butylphenol at $60{ }^{\circ} \mathrm{C}$ and $600 \mathrm{rpm}$. Table 3 shows the kinetics of 4 -tert-butylphenol with 1-bromobutane in the presence of various catalysts. A various catalyst MPTC showed higher reactivity because of the presence of two active sites. The higher efficiency of MPTC further attributed to high lipophilic character of the cation $\mathrm{Q}^{+}$supplied by the MPTC catalyst leads to the formation of ion pair $\mathrm{Q}^{2+}\left(\mathrm{C}_{10} \mathrm{H}_{13} \mathrm{O}\right.$ $\mathrm{K}^{+}$). The ion pairs are easily enter in to the organic phase where displacement reaction takes place order of catalytic activity of all catalysis was presented here: MPTC $>$ TOAB $>$ THAB $>$ TBAI $>$ TBAB $>$ TBAC.

\subsection{Effect of Organic Solvents}

In this work, the influence of different organic solvents on the rate of $\mathrm{O}$-alkylation of 4-tert-butylphenol was followed under typical reaction conditions. Dielectric constant of the medium plays an important role in bringing reaction faster. Hence, different solvents employed in this investigation are chlorobenzene, ethyl acetate, toluene, benzene, and cyclohexane dielectric constant was used to study the influence of solvent on reaction rate. The order of the relative activities of these organic solvents is as follows: chlorobenzene $\left(\mathrm{C}_{6} \mathrm{H}_{5} \mathrm{Cl}\right)>$ ethylacetate $\left(\mathrm{C}_{4} \mathrm{H}_{8} \mathrm{O}_{2}\right)>$ toluene $\left(\mathrm{C}_{7} \mathrm{H}_{8}\right)>$ benzene $\left(\mathrm{C}_{6} \mathrm{H}_{6}\right)>$ cyclohexane $\left(\mathrm{C}_{6} \mathrm{H}_{10}\right)$. From Table 4 , it was induced that solvent with more dielectric constant showed better rate than solvent of low dielectric constant. The increased rate constant is attributed to the increase in the dielectric constant of the organic solvent.

\subsection{Reaction Mechanism}

The experimental consequences from the present kinetic work specify that the dependency of the kinetic data on the whole over of agitation speed, potassium hydroxide, amount of multi-site phase transfer catalyst, temperature, and higher activation energy value are in-

Table 3. Influence of various phase transfer catalyst on the reaction condition: $10 \mathrm{~g}$ of $\mathrm{KOH}$, in $3 \mathrm{~mL}$ $\mathrm{H}_{2} \mathrm{O}, 0.2 \mathrm{~g}$ of biphenyl (internal standard), $13.31 \mathrm{mmol}$ of 4 -tert-butylphenol, $13.31 \mathrm{mmol}$ of 1 bromobutane, $30 \mathrm{~mL}$ of chlorobenzene, $60^{\circ} \mathrm{C}, 600 \mathrm{rpm}$.

Phase Transfer Catalyst (3 mol\%) Structure


dicative of an interfacial mechanism. Mostly, the hydroxide anion deprotonates 4-tertbutylphenol at the interphase, forming an ion pair $\mathrm{C}_{10} \mathrm{H}_{13} \mathrm{O}^{-} \mathrm{K}^{+}$. In the lead addition of the catalyst (MPTC) $\mathrm{Q}^{+} \mathrm{X}$, the ion exchange has been taken place at the interfaces $\left(\mathrm{C}_{10} \mathrm{H}_{13} \mathrm{~K}\right.$ $\mathrm{Q}^{+}$), and the new formed ion pair $\mathrm{C}_{10} \mathrm{H}_{13} \mathrm{~K}^{\cdot} \mathrm{Q}^{+}$

Table 4. Influence of organic solvents on the reaction condition: $10 \mathrm{~g}$ of $\mathrm{KOH}$, in $3 \mathrm{~mL} \mathrm{H}_{2} \mathrm{O}$, $0.2 \mathrm{~g}$ of biphenyl (internal standard), 13.31 mmol of 4-tert-butylphenol, $13.31 \mathrm{mmol}$ of 1 bromobutane, $3 \mathrm{~mol} \%$ of MPTC, $60{ }^{\circ} \mathrm{C}, 600 \mathrm{rpm}$.

\begin{tabular}{lcc}
\hline \multicolumn{1}{c}{ Solvents } & $\begin{array}{c}\text { Dielectric } \\
\text { constant }\end{array}$ & $\begin{array}{c}k_{\text {app }} \times 10^{-3}, \\
\mathrm{~min}^{-1}\end{array}$ \\
\hline Chlorobenzene & 5.60 & 22.32 \\
Ethylacetate & 3.01 & 18.24 \\
Toluene & 2.40 & 14.47 \\
Benzene & 2.30 & 10.82 \\
Cyclohexane & 2.01 & 9.43 \\
\hline
\end{tabular}

(Scheme 3) which is an extra additional organophilicity and therefore there is an easy migration in to the organic phase. The ion pair reacts with 1-bromobutane (BB) present in the organic phase resulting in the formation of 1-butoxy4 -tert-butylbenzene as intend organic compound.

\section{Conclusion}

In this present work, synthesis of 1-butoxy4-tert-butylbenzene from the reaction of from 4-tert-butylphenol and 1-bromobutane (BB) under synthesized multi-site phase transfer catalyst (MPTC) was successfully carried out using a well powdered of $\mathrm{KOH}$ and organic solvent biphasic medium. The appropriate reaction mechanism was verified by the experimental evidence, and the apparent rate constant was obtained from the experimental result. The apparent reaction rate was obtained to follow the pseudo first order kinetics. The apparent rate constant was found to directly dependent on every kinetic parameters, such as: multi-site phase transfer catalyst (MPTC), potassium hy-

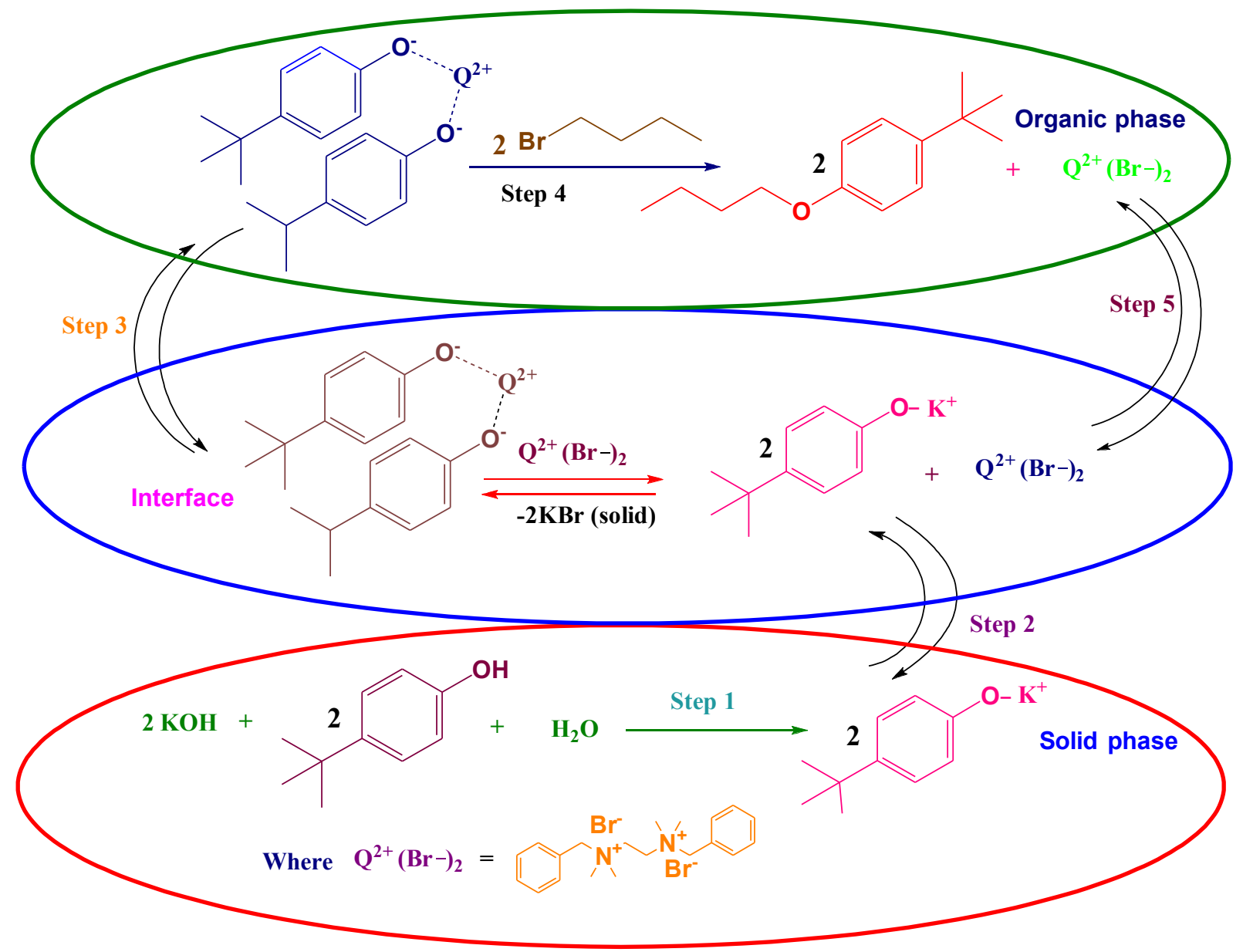

Scheme 3. General reaction mechanism. 
droxide $(\mathrm{KOH})$, agitation speed, and temperature. Nevertheless, it decreases with increases in the amount of water. The reaction rate is decreased by increasing the volume of chlorobenzene. The activation energy $\left(E_{\mathrm{a}}\right)$ was also calculated through the Arrhenius plot.

\section{Acknowledgments}

The authors would like to thank Pachaiyappa's Trust and Pachaiyappa's College, Chennai, Tamil Nadu, India-600 030, for their grant permission to do this research work.

\section{References}

[1] Rasmussen, J.K., Smith, H.K. (1981). Phase transfer free radical reactions: The Crown ether potassium peroxy disulphate initiator system. Journal of American Chemical Society, 103, 730-736.

[2] Wang, M.L., Hsieh, Y.M. (2004). Kinetic study of dichlorocyclopropanation of 4-Vinyl-1cyclohexene by a Novel Multisite Phase Transfer Catalyst. Journal of Molecular Catalysis A: Chemistry, 210, 59-68.

[3] Vajjiravel, M., Umapathy, M.J. (2010). Synthesis, characterization and application of a multi-site phase transfer catalyst in radical polymerization of n-butyl methacrylate-a kinetic study. International Journal of Polymeric Materials, 59, 647-662.

[4] Makosza, M., Fedorynski, M. (2012). Phase Transfer Catalysis - Basic Principles, Mechanism and Specific Features. Current Catalysis, 57, 79-87.

[5] Yadav, G. D. (2004). Insight into green phase - transfer catalysis. Topics in Catalysis, 29, 145-161.

[6] Jones, R.A. (2001). Quaternary Ammonium Salts: Their Use in PhaseTransfer Catalysed Reactions. Academic Press: U.K.

[7] Ocic, O. (2005). Oil Refineries in the 21st Century: Energy Efficient, Cost Effective, Environmentally Benign; John Wiley \& Sons: New York.

[8] Murugan, E., Tamizharasu, G. (2012). Synthesis and Characterization of New Soluble Multisite Phase Transfer Catalysts and Their Catalysis in Free Radical Polymerization of Methyl Methacrylate Aided by Ultrasound - A Kinetic Study. Journal of Applied Polymer science, 125, 263-273.

[9] Vivekanand, P.A., Balakrishnan, T. (2009). Kinetics of dichlorocyclopropanation of vinylcyclohexane catalysed by a new multi-site phase transfer catalyst. Catalysis Communication, 72, 687-692.
[10] Wang, M. L., Lee, Z.F., (2006). Reaction of 4,4-bis (chloromethyl)-1,10-biphenyl and Phenol in two-phase medium via phase-transfer catalysis. Journal of Molecular Catalysis A: Chemistry, 264, 19- 127.

[11] Loganathan, S., Rajendran, V. (2013). Ultrasound assisted polymerization of $\mathrm{N}$-vinyl imidazole under phase-transfer catalysis condition - A kinetic study. Ultrasonics Sonochemistry, 20, 308-313.

[12] Mason, D., Magdassi, S., Sasson, Y. (1991). Role of a third liquid phase in phase-transfer Catalysis. Journal of Organic Chemistry, 56, 7229- 7232 .

[13] Abimannan, P., Rajendran, V. (2016). Kinetic Study for the Synthesis of 1-nitro-4-(prop-2yn yloxy) benzene in Solid-Liquid PTC Condition. Current Catalysis, 5, 44-50.

[14] Selvaraj, V., Rajendran, V. (2013). Preparation of 1,3-bis(allyloxy)benzene under a New multi- site phase-transfer catalyst combined with ultrasonication - A kinetic study. Ultrasonics Sonochemistry, 20, 1236-1244.

[15] Idoux, J.P., Wysocki, R., Young, S., Turcot, J., Ohlman, C., Leonard, R. (1983). polymersupported "multi-site" phase transfer catalysts. Synthetic Communication, 13, 39-144.

[16] Vivekanand, P.A., Balakrishnan, T. (2009). Superior catalytic efficiency of a new multisite Phase transfer catalyst in the Calkylation of dimedone - a kinetic study. Catalysis Communication, 10, 1371- 1375.

[17] Balakrishnan, T., Jeyachandran, J.P. (1995). New multi-site phase transfer catalyst for the addition of dichlorocarbene to styrene. Journal of Chemical Society: Perkin Trans, 2, 2081- 2085.

[18] Balakrishnan, T., Shanmugan, K. (2007). New multi-site phase transfer catalyst for the addition of dichlorocarbene to olefins. Indian Journal of Chemistry A, 46, 1069-1074.

[19] Murugan, E., Tamizharasu, G. (2012). New soluble multi-site phase transfer catalysts and their catalysis for dichlorocarbene addition to citronellal assisted by ultrasound-A kinetic study. Journal of Molecular Catalysis A: Chemistry, 364, 81-89.

[20] Wang, M.L., Lee, Z.F. (2006). Synthesis of Novel Multisite Phase-Transfer Catalysts and Their Applications to the Catalyzed Reaction of Bisphenol A and Allyl Bromide. Industrial Engineering Chemistry Research, 45, 4918-4926.

[21] Balakrishnan, T., Murugan, E., Siva, A. (2004). Synthesis and characterization of novel soluble multi-site phase transfer catalyst; its efficiency compared with single-site phase transfer catalyst in the alkylation of phe- 
nylacetonitrile as a model reaction. Applied Catalysis A: General, 273, 89-97.

[22] Harikumar, K., Rajendran, V. (2014). Ultrasound assisted the preparation of 1-butoxy-4nitrobenzene under a new multi-site phasetransfer catalyst - Kinetic study. Ultrasonics Sonochemistry, 21, 208-215.

[23] Brahmayya, M., Wang, M.L. (2016). Kinetic study for benzyloxylation of p-bromotoluene using phase transfer catalyst assisted by microwave irradiation. Journal of Taiwan Institute of Chemical Engineering, 000, 1-7.

[24] Vajjiravel, M., Marimuthu, E., Yoganand, K.S., Umapathy, M.J. (2017). Multi-site phase transfer catalyzed radical polymerization of methyl methacrylate in mixed aqueous-organic medium: a kinetic study. International Journal of Industrial Chemistry, 8, 241-251.

[25] Vajjiravel, M., Umapathy, M.J. (2016). Phase transfer catalyst aided radical polymerization of n-butyl acrylate in two-phase system: a kinetic study. International Journal of Industrial Chemistry, 7, 441-448.

[26] Wang, M.L., Rajendran, V. (2007). Ultrasound assisted phase-transfer catalytic epoxidation of 1,7-octadiene - A kinetic study. Ultrasonics Sonochemistry, 14, 46-54.
[27] Murugan, E., Siva, A. (2006). New trimeric Cinchona alkaloid-based quaternary Ammonium salts as efficient chiral phase transfer catalysts for enantioselective synthesis of a-amino acids. Journal of Molecular Catalysis A: Chemistry, 248, 1-9.

[28] Kirsten, T.A., Olov, S., Christer, H. (2000). Tyrosinase-Mediated Formation of a Reactive Quinone from the Depigmenting Agents, 4tert-Butylphenol and 4-tert-Butylcatechol. Pigment Cell Research, 13, 33-38.

[29] Starks, M., Liotta, C.L., Halpern, M. (1994). Phase Transfer Catalysis, Fundamentals, Applications, and Industrial Perspectives, Chapman \& Hall, New York.

[30] Makosza, M., Fedorynski, M. (2003). Phase Transfer Catalysis. Catalysis Reviews, 45, 321-367

[31] Wang, M.L., Hsieh, Y.M., Chang, R.Y. (2003). Kinetics study of dichlorocyclopropanation of 1,7-octadiene under phase transfer catalysis conditions at high alkaline concentration. Industrial \& Engineering Chemistry Research, 42, 4702-4707. 